\title{
A Vida Social dos Instrumentos Musicais de Eliot Bates
}

The Social Life of Musical Instruments by Eliot Bates

Ricardo Cappra Pauletti ricardopauletti@yahoo.com.br

Mestre em Música / UDESC 


\section{Resumo}

Este trabalho apresenta uma resenha sobre o artigo de Eliot Bates (2012) A Vida Social dos Instrumentos Musicais. O autor faz uma reflexão sobre a organologia onde critica os antigos sistemas classificatórios, comenta importantes trabalhos sobre 0 tema e propõe um novo paradigma baseado na Teoria Ator-Rede.

Palavras-chave: Organologia, Instrumentos Musicais, Teoria Ator-Rede, Eliot Bates.

\section{Abstract}

This paper presents a review on the article The Social Life of Musical Instruments by Eliot Bates (2012). Bates makes a reflection about organology, criticizes the old classificatory systems, comments on important works about organology and proposes a new paradigm based on the Actor-Network Theory

Keywords: Organology, Musical instruments, Actor-Network Theory, Eliot Bates. 


\section{Introdução}

A organologia - ciência que estuda os instrumentos musicais - ainda está diretamente associada aos sistemas de classificação e aos museus. Ao longo da história, existem registros de sistemas classificatórios em diferentes culturas e épocas, inclusive sistemas milenares como os da China e Índia. Porém, somente no século XIX iniciou-se na Europa uma metodologia científica para as classificações (OLIVEIRA PINTO, 2001), (NETTL, 1983).

O sistema que se tornou mais conhecido é o de Hornbostel e Sachs (1914), que foi inspirado no de Mahillon (1880), por sua vez inspirado no milenar sistema indiano, onde os instrumentos musicais são divididos em quatro famílias e cada uma delas em diferentes categorias:

1- Idiofones: o som é gerado através da vibração do material do próprio corpo;

2- Membranfones: o som é gerado através da vibração de uma membrana;

3- Cordofones: o som é gerado através da vibração de cordas;

4- Aerofones: o som é gerado através da vibração ocasionada por uma coluna de ar.

Posteriormente foi incluída uma quinta categoria, os "eletrofones".

Atualmente, a organologia apresenta preocupações que vão bem além de um sistema classificatório. Neste sentido, surgem alguns trabalhos que debatem o assunto com mais profundidade, como o artigo $A$ vida social dos instrumentos musicais de Eliot Bates (2012).

\section{A vida social dos instrumentos musicais}

Bates utiliza exemplos da literatura e do cinema para ilustrar casos em que instrumentos musicais deixam de ser simples objetos, podendo muitas vezes assumir papel de protagonistas de uma história. Eles podem criar afetos e despertar o desejo, não são “... artefatos passivos que emanam som, eles estão emaranhados em teias de relações complexas - entre humanos e objetos, entre humanos e humanos e entre objetos e objetos." (BATES, 2012, p. 364). Além disso, um mesmo instrumento em diferente contexto histórico social terá diferentes tipos de relações.

Em seguida, Bates entra no tema "organologia". Ele comenta que essa expressão ainda está vinculada ao sistema classificatório de Hornbostel-Sachs e aos museus. Ele considera "uma classe ultrapassada de mensuração e documentação de objetos físicos" (BATES, 2012, p. 365), dizendo que, nos museus, os instrumentos tornam-se objetos mórbidos exibindo musicalidades mortas e encontram-se desprovidos de história.

Bates cita trabalhos que foram além dos tradicionais sistemas classificatórios. Ki Mantle Hood (1985) acreditava que um sistema de classificação deveria dar conta de detalhes como o som musical e a função social dos instrumentos. Criou um sistema de organogramas com uma série de informações, inclusive relações dos instrumentos 
com os indivíduos e a sociedade, que para Bates não transmitem a natureza dinâmica e variável das relações pessoais e sociais com instrumentos. Para Sue DeVale o objetivo final da organologia é "...ajudar a explicar a sociedade e a cultura" (DEVALE, 1990, p. 22 apud BATES, 2012, p. 367) onde sua essência pode estar contida nos instrumentos musicais. DeVale sugere um pensar através dos instrumentos com dois exemplos distintos: a teoria de instrumentos-espíritos em rituais e a história de vida de um Gamelão na Exposição Universal de Chicago. Cinco décadas antes de DeVale, Robert Van Gulik's (1940) analisou o Ch'in-pu (um tipo de alaúde) sobre diversos aspectos e também analisou os numerosos manuais para alaudistas, que continham muitos detalhes sobre o instrumento, como construção, cordas e técnicas para tocar.

Bates também comenta sobre trabalhos mais recentes que vêm apresentando novas abordagens e visões sobre questões relacionadas a pesquisas com instrumentos musicais. Regula Qureshi (2000) escreveu sobre o sarangi indiano, explorando a inter- relação entre as estéticas audíveis, simbolismos instrumentais e debates sobre a adequação de certos contextos de desempenho para tocar o instrumento. Ele fala que é necessário "uma vontade de expandir os estudos de música de seu casulo de gozo estético e sonoro convencionalizado, a fim de permitir que as implicações políticas e históricas venham à tona." (QURESHI, 2000, p. 808 apud BATES, 2012, p. 368). O trabalho de Qureshi foi o primeiro a ligar estudos antropológicos do corpo e incorporação ao domínio de instrumentos musicais e instrumentais sonoros. Bates relata que Kevin Dawe pesquisou em Creta uma pequena rabeca indígena chamada Lira, observando festivais, construtores, amplificação e visibilidade na Creta contemporânea. Dawe sugere que "os instrumentos musicais podem transformar mentes e corpos, afetando estados de espírito, tanto quanto articulações, tendões e sinapses" (BATES, 2012, p. 368). Na pesquisa de Dawe, os instrumentos também assumem o papel de sujeito, deixando de ser apenas objetos - o que o autor considera "pensar através dos instrumentos". Para Dawe, existe um poder transformador dos instrumentos tornando-se ativos na formação da vida social e cultural. "Eles existem em redes de cultura, envolvidos em uma série de discursos e intrigas políticas, e ocupam posições de definição de status. Instrumentos musicais são vistos como construções materiais e sociais" (DAWE, 2007, p. 114 apud BATES, 2012, p. 368). Outro trabalho destacado por Bates é o de John Baily sobre o dutar, em que são discutidas inovações na construção de instrumentos, cinestesia e a situação sociomusical complexa e dinâmica que envolve mudanças na estrutura da música e mudanças na posição social de música e músicos. Baily foi um dos primeiros etnomusicólogos a realizar um estudo prolongado da cinestesia de tocar em relação à morfologia do instrumento. "Para Baily, a relação entre cinestesia e morfologia influencia diretamente a natureza do gênero musical" (BATES, 2012, p. 369). Dessa forma, o instrumento e suas particularidades físicas podem formatar a música. Outro trabalho citado por Bates é o de Partow Hooshmandrad, que defende a ideia de uma "organologia vivida" baseada em histórias, significados históricos e análise da função de instrumentos musicais em relações humano-divinas. Ela também analisa a produção de "Ustād Asad Allāh", um importante construtor de tanbur. 
Após analisar cada um destes trabalhos descritos, tecendo algumas críticas e apontando limitações específicas, Bates inicia o capítulo A vida social dos objetos, falando sobre o novo paradigma que está construindo para abranger toda a gama de possíveis relações entre homem-objeto-divino, podendo ser visto na construção de instrumentos, performances, cura musical e numerosos outros campos e domínios. Neste novo paradigma, o instrumento musical passa a ser constitutivo na ação social e não meramente incidental. Ele fala da complexidade para uma abordagem que analise a relação entre humanos e objetos não humanos e sugere utilizar a "Teoria Ator-Rede" (Actor-Network Theory - ANT) ${ }^{1}$.

Nesta teoria, os objetos passam a ser também atores e se relacionam com os humanos em uma complexa rede. Ela não define o ator nem como sujeito nem como objeto, mas como uma fonte de ação integrante da rede, que por sua vez é heterogênea e marcada por ter múltiplas conexões e entradas. Esta abordagem também levanta questões importantes sobre como analisar a temporalidade das redes, e mais amplamente como teorizar cultura, contexto ou comunidade.

Bates segue o texto relatando sua experiência de pesquisa com instrumentos musicais. Relata que, na Turquia, entrou em contato com dois instrumentos tradicionais turcos - o Ud e o Saz (espécies de alaúdes) - os quais ele analisa sob esse novo paradigma, procurando entender sua vida social e a heterogeneidade da rede de relações em que estão inseridos. Ele analisa o Saz e a canção, identificando a presença do Saz nas letras de músicas, onde percebe que nessas letras ele aparece com características humanas como infiel, opressivo e cruel. O segundo aspecto é o Saz e a nação, onde o Saz aparece como instrumento nacional, constitutivo dos ideais de uma nação (Turquia) e associado a um território e uma identidade social. $O$ terceiro aspecto refere-se às questões construtivas do Saz, mostrando as limitações do sistema Horbostel-Sachs, onde o Saz pode se enquadrar em duas classificações diferentes, ou receber a mesma classificação de outros instrumentos. O autor descreve duas maneiras de se fabricar o Saz, uma artesanal e outra feita em série, em uma fábrica. $O$ instrumento artesanal tem um corpo escavado em uma peça única de madeira e é feito com o contato do mesmo artesão em todo o processo de construção. O produzido em série tem cada etapa do processo de construção conduzida por diferentes profissionais e, ao invés do corpo escavado em uma peça única, tem o corpo fabricado com diferentes peças de madeiras coladas (para baratear a produção). O resultado é um instrumento único com maior qualidade produzido pelo artesão e um instrumento padronizado com qualidade inferior produzido em série pela fábrica. Por último, o autor analisa o Saz e suas partes constituintes, onde cada parte do instrumento está relacionada à anatomia humana, tendo: um corpo, um braço ou pescoço, um peito, um rosto e sete orelhas. Sob outros aspetos, ele ainda pode tornar-se uma arma, ou fazer um estrangeiro tornar-se mais turco.

Em suas conclusões, Bates levanta questionamentos que ele julga importantes para a chamada "organologia vivida", tais como:

1 A Teoria Ator-Rede tem como principal expoente o sociólogo, antropólogo e filósofo francês Bruno Latour (n. 1947), ao lado de Michel Callon (n. 1945) e John Low (n. 1946), onde o ator pode ser "qualquer pessoa, instituição ou coisa que tenha agência, isto é, produza efeitos no mundo e sobre ele." (MORAES, 2013, p. 322) 
- É o instrumentista que molda o instrumento, ou o contrário?

- Por que alguns instrumentos musicais estão repletos de simbolismo e associações simbólicas enquanto outros não?

- Por que alguns (mas não todos) instrumentos antropomorfizaram; por exemplo, a ponto de serem considerados capazes de chorar ou sentir tristeza?

- Porque existe uma resistência à adoção de versões ergonomicamente "melhoradas" de alguns instrumentos, e o que a resistência nos diz sobre as relações instrumento instrumentista?

- Até que ponto novas técnicas de construção, novos materiais, ou alterações de aspectos formais podem resultar em um novo instrumento?

\section{Considerações Finais}

O artigo de Bates lança novos olhares para os estudos de instrumentos musicais. Apresenta uma forte crítica à antiga organologia dos sistemas classificatórios e propõe uma nova abordagem baseada na Teoria Ator-Rede de Bruno Latour, admitindo que os instrumentos encontram-se emaranhados em uma complexa rede de relações e podem - da mesma forma que os humanos - assumir papel principal em determinados contextos.

Acredito que a crítica de Bates aos "antigos" e "ultrapassados" sistemas de classificação como o de Hornbostel-Sachs é de certa forma exagerada, pois mesmo com todas as limitações, eles podem ter sua utilidade e importância. Além disso, serviram de base e inspiração para se pensar novos sistemas mais eficientes e menos limitados, como mostra os estudos de Kartomi (1990).

Embora o trabalho de Bates não me pareça ter alcançado o objetivo de traçar um "novo paradigma" para a organologia (como ele sugere), a aplicação da Teoria Ator-Rede pode ajudar bastante na compreensão de determinadas culturas através da análise de seus instrumentos musicais e suas redes de relacionamentos, oferecendo um excelente caminho para o pesquisador.

\section{REFERÊNCIAS}

BATES, Eliot. The social life of musical instruments. Ethnomusicology, v. 56, p. 363-395, 2012.

KARTOMI, Margaret. On Concepts and Classifications of Musical Instruments. Chicago:

University of Chicago Press, 1990.

MORAES, Márcia. A ciência como rede de atores: ressonâncias filosóficas. História, Ciências, Saúde - Manguinhos, vol. 11(2): 321-33, maio-ago. 2004. 
NETTL, Bruno. The Study of Ethnomusicology: Thirty-one Issues and Concepts. Chicago: University of Illinois Press, 1983.

OLIVEIRA PINTO, Tiago de. Som e música. Questões de uma Antropologia Sonora. Revista Antropologia. São Paulo, USP, v.44, n.1, p. 221-286, 2001. 